\title{
Trichilemmomal Horn Arising from a Nevus Sebaceus and Pilar Cyst: A Case Report and Review of the Literature
}

\author{
Elizabeth Peacock, Navid Ezra, Konstantinos Linos, Lawrence A. Mark \\ Department of Dermatology, Indiana University School of Medicine, Indianapolis, USA \\ Email: lamark@iu.edu
}

Received 4 September 2015; accepted 12 October 2015; published 15 October 2015

Copyright $@ 2015$ by authors and Scientific Research Publishing Inc.

This work is licensed under the Creative Commons Attribution International License (CC BY). http://creativecommons.org/licenses/by/4.0/

(c) (i) Open Access

\begin{abstract}
Nevus sebaceus can give rise to multiple neoplasms, some of which have the potential to become malignant. We describe the occurrence of a previously unreported combination of a cutaneous horn proliferating from a trichilemmoma overlying a multilocular pilar cyst and nevus sebaceus. An elderly woman with a several years' history of multiple scalp subcutaneous nodules and an enlarging cutaneous horn presented to our clinic. The nodule underlying the large exophytic horn was tender and occasionally bled. The lesion was removed by excisional biopsy due to concern for malignancy. Histologically, a verrucous trichilemmoma was identified overlying irritated pilar cysts and a nevus sebaceus. Phosphatase and tensin homolog (PTEN) mutations are frequently found in trichilemmomas and HRAS mutations in nevus sebaceus. Mammalian target of rapamycin (mTOR) is a part of the final common pathway for HRAS and PTEN raising the therapeutic question if rapamycin can be used to treat these neoplasms.
\end{abstract}

\section{Keywords}

Trichilemmoma, Pilar Cyst, Nevus Sebaceus, Cutaneous Horn

\section{Introduction}

Headington and French originally described trichilemmomas as benign follicular tumors of the outer root sheath that clinically presented as nodular, flesh colored papules that could have smooth or verrucoid surfaces [1]. Cowden syndrome often presents with multiple trichilemmomas and is most common in middle aged Caucasian women [2]. The solitary trichilemmoma is a relatively common solid benign neoplasm that can produce a hyperkeratotic surface as it enlarges, namely a cutaneous horn [3]. Nevus sebaceus and pilar cysts can be found 
in association with malignant tissue. This case reports an elderly female with a rare combination of trichilemmomal horn, nevous sebaceus and pilar cyst that was treated with excision without local recurrence at two-year follow-up. Prior to her procedure, patient was given a 10-day course of cephalexin by the Emergency Department given concern for possible infectious component contributing to the enlarging and tender mass.

\section{Case Report}

An 83-year-old female presented to dermatology clinic with a several years' history of multiple subcutaneous nodules on the scalp and an enlarging cutaneous horn. She had a past medical history including coronary artery disease, cerebral vascular accident, hypertension, arthritis and chronic kidney disease. Overlying the occipital scalp nodule was a $5 \mathrm{~cm}$ by $3 \mathrm{~cm}$ brown keratinized spiral horn (Figure 1). The nodule underlying this exophytic horn was tender and occasionally bled. The lesion was removed by excisional biopsy due to concern for pilar carcinoma and squamous cell carcinoma. On histopathologic examination, there was a prominent basement membrane, clear cell changes, squamous eddies, and an exophytic as well as endophytic component, all consistent with a verrucous trichilemmoma (Figure 2 and Figure 3). Underlying the aforementioned, a multilocular pilar cyst, focally irritated and ruptured, was identified (Figure 4). In addition, foci of immature hair follicles with sebaceous gland hyperplasia suggested the underlying process of nevus sebaceus (Figure 5). There was no histopathologic evidence of malignancy. The patient has now been followed for two years and while she has many other pilar cysts remaining and developing on her scalp, the lesion that was excised has not recurred and no further trichilemmomal horns have developed.

\section{Comment}

Cutaneous horns growing from trichilemmomas, termed trichilemmomal horns, must be differentiated from trichilemmal horns which show trichilemmal rather than epidermal keratinization. Trichilemmal horns also tend to have multiple cysts that open to the surface and are found more frequently on the limb or back as opposed to the scalp [4].

Cutaneous horns consist mostly of keratin and are more likely to occur in middle-aged or elderly light skinned male individuals in sun exposed areas often overlying another cutaneous lesion [5]. Cutaneous horns are reported to arise from premalignant or malignant lesions in $38.9 \%$ of cases [6].

Trichilemmomas can be associated with a mutation in phosphatase and tensin homolog (PTEN) gene. PTEN is a tumor suppressor gene that regulates the phosphatidylinositol-4,5-bisphosphate 3-kinase/protein kinase B (PI3K/Akt) pathway to prevent uncontrolled cell proliferation [7]. An inactivating mutation to PTEN leads to an unregulated PI3K/Akt pathway and hence reduced apoptosis and increased cell division (Figure 6).

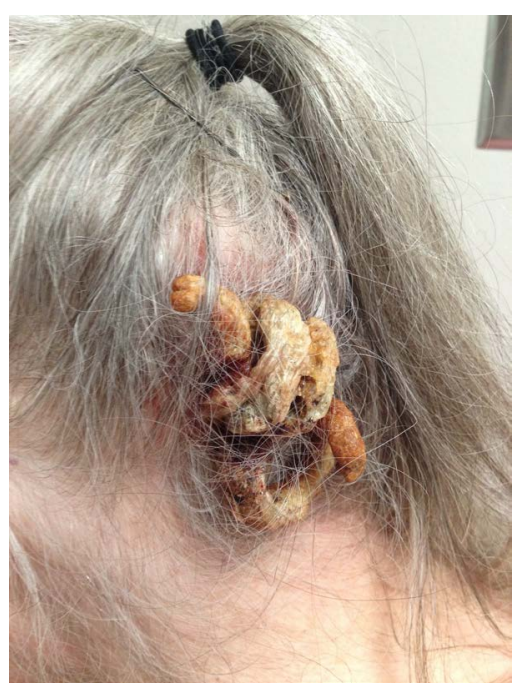

Figure 1. Brown, spiral, exophytic cutaneous horn on left occipital scalp. Just superior and only partially visible is an irregular subcutaneous nodule with associated alopecia. 


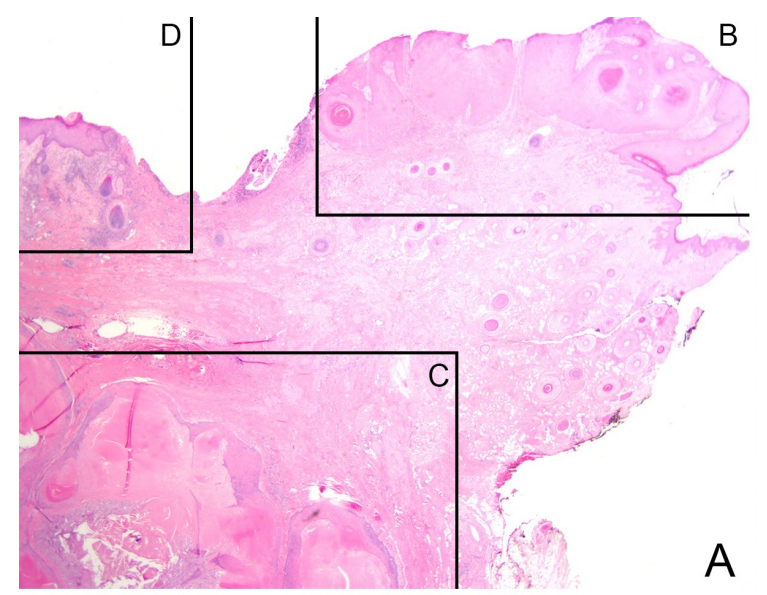

Figure 2. (A) Scanning magnification showing the three components of trichilemmoma (B), mutilocular pilar cyst (C) and changes suggestive of nevus sebaceus (D). In other sections a more exophytic architecture of the trichilemmomatous component was evident (H\&E 20×).

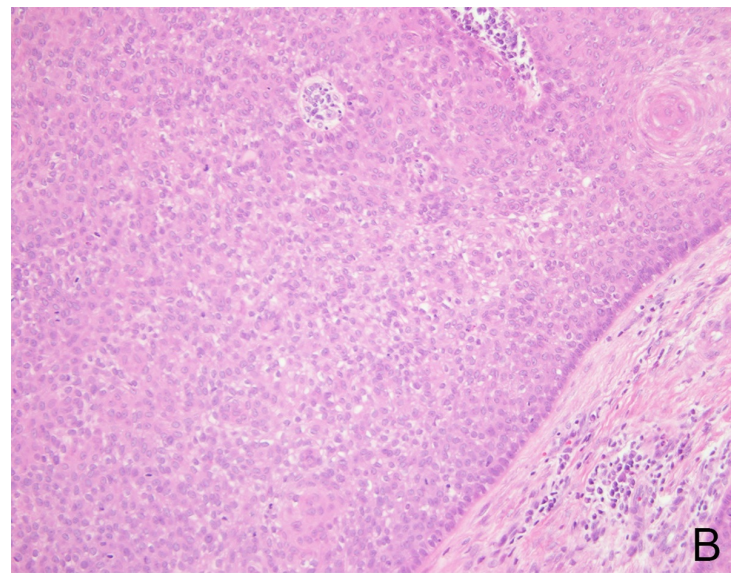

Figure 3. Higher magnification of section B from Figure 2 depicting the trichilemmoma showing prominent basement membrane, clear cell changes and squamous eddies (H\&E 200×).

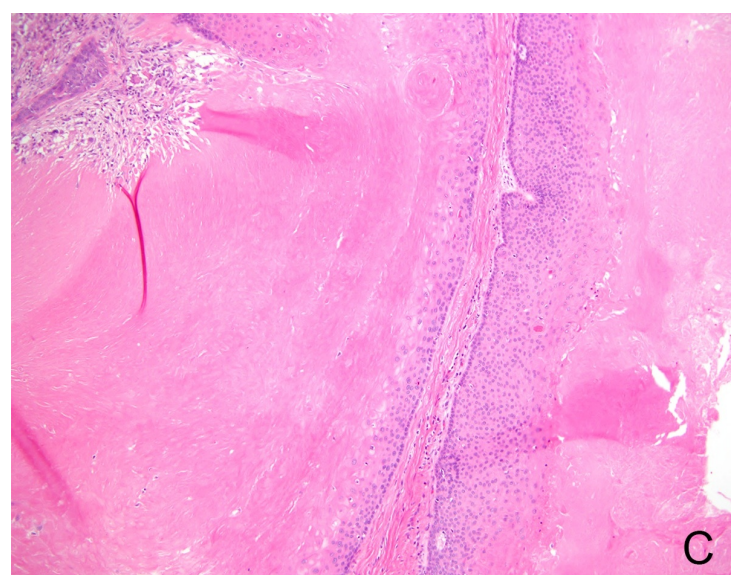

Figure 4. Higher magnification of section C from Figure 2 showing the multilocular pilar cyst composed of bland squamous epithelium without granular cell layer with abrupt dense keratinization (H\&E 200×). 


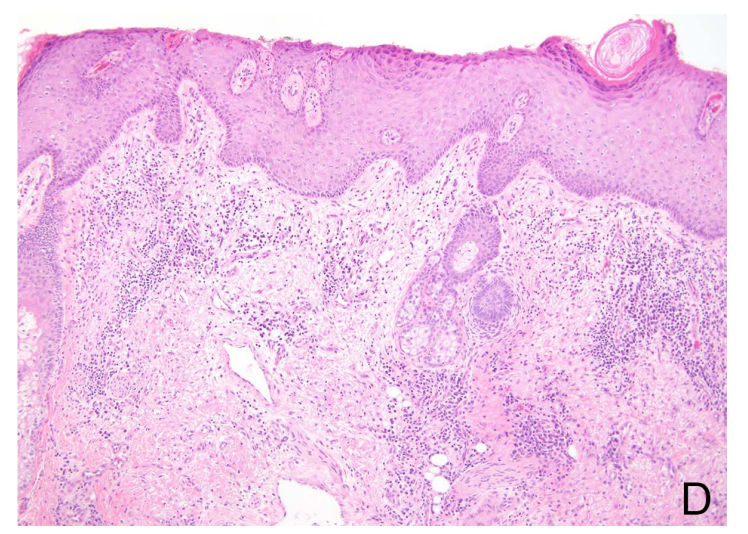

Figure 5. Medium power of section D from Figure 2 showing foci of immature hair follicles with some sebaceus gland hyperplasia suggestive of nevus sebaceus (H\&E 100×).

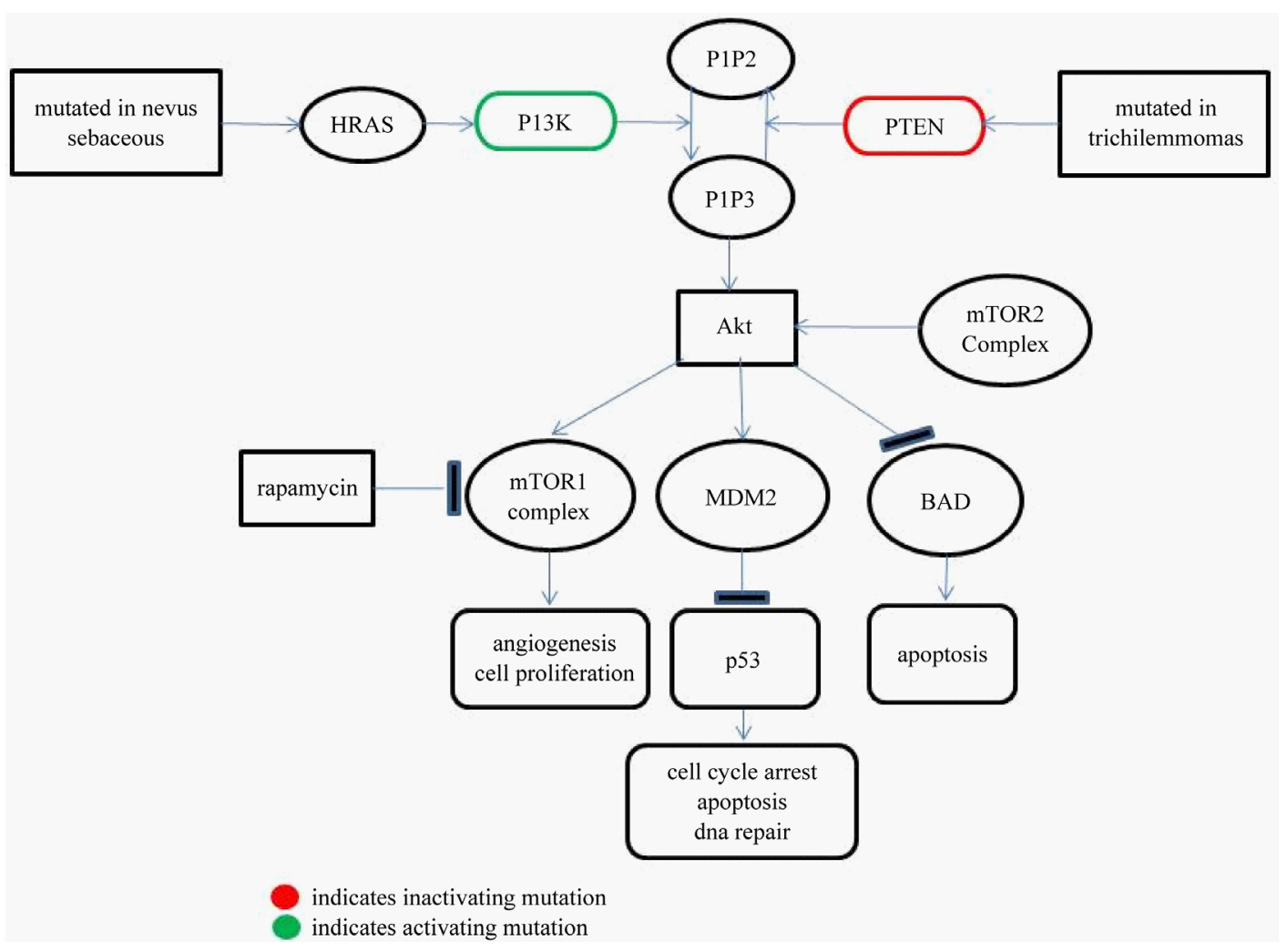

Figure 6. Cell signaling pathway depicting the interaction between PTEN, HRAS and the PI3K/Akt pathway.

The nevus most commonly associated with trichilemmoma is nevus sebaceus [3]. Nevi sebacei are congenital, hairless plaques that most commonly occur on the face or scalp and can become more pronounced around puberty and adulthood [8] [9]. These lesions affect both genders and all races equally. Secondary adnexal neoplasms often develop from nevus sebaceus [2] [8] [9].

HRAS mutations are often found in nevus sebaceus [10]. The presence of an HRAS mutation in nevus sebaceus is associated with secondary tumors developing within the neoplasm [11]. HRAS is a GTPase that responds to growth factors and recruits proteins such as PI3K. HRAS can be mutated so that it is constitutively activated thus leading to an uncontrolled cell proliferation [10] [11]. Both the PTEN mutations found in trichilemmomas and HRAS mutations found in nevus sebaceus lead to overactive cell division and reduced apoptosis by the PI3K/Akt pathway (Figure 6). 
Mammalian target of rapamycin (mTOR) is a part of the final common pathway for HRAS and PTEN. As such, mTOR is a likely target for therapies of neoplasms involving the PI3K/Akt pathway such as trichilemmomas and nevus sebaceus. Rapamycin and sirolimus have been shown to inhibit mTOR [12]. There is currently a clinical trial studying sirolimus in the treatment of Cowden syndrome and other PTEN hamartomatous tumor syndromes.

There are two mTOR complexes-mTOR complex one (mTORC1) and mTOR complex two (mTORC2) [13]. Rapamycin inhibits mTORC1 which functions to downregulate the Akt cell growth pathway [7] [12]. Long term use of rapamycin might inhibit mTORC2 which would further prevent Akt activation [11] [12]. However, studies of solid tumors revealed that rapamycin only inhibits some actions of mTOR [12]. In solid tumors, inhibiting mTORC1 can actually activate extracellular signal-related kinase (ERK) and stimulate cell division [12]. In addition, mTORC2 is sometimes rapamycin insensitive [13]. Also, inhibiting mTORC1 may increase activity of mTORC2 leading to Akt hyperactivity [12]. The interaction between Akt and mTOR is complex as they are linked by both positive and negative regulation [12] [13]. Further study of the drug including clinical trials are necessary to fully elucidate the impact of rapamycin on solid tumors such as trichilemmomas and nevus sebaceus.

Pilar cysts are firm, subcutaneous, keratin-filled cysts that originate from the outer root sheath of the hair follicle [3]. Pilar cysts are frequently found on the scalp of middle-aged and elderly woman. The pilar cyst is sharply demarcated from surrounding tissue and has its origin in the deep dermis where it grows slowly for years [14].

The decision for treatment by excision was multifold given the malignant potential for the lesion, the increasing discomfort experienced by the patient, and the desire for some component of cosmesis. Diagnosis was confirmed after extensive review of the slides by dermatopathology.

\section{Conclusions}

Cutaneous horns, nevus sebaceus, pilar cysts and trichilemmomas all have the potential to arise from malignant lesions or become malignant themselves [5] [14]. These lesions may be removed for cosmesis or if there is concern for malignancy [15]. Appropriate treatment is excisional biopsy with further treatment directed by results of histological analysis [9]. Dermatopathologic review of this patient's lesion did not reveal malignancy and thus she was followed clinically. She was offered a referral to plastic surgery for removal of her other numerous pilar cysts on the scalp.

Adnexal neoplasms are frequently reported as developing from nevus sebaceus. However, this is the first report in the literature of which we are aware describing the combination of a trichilemmoma, cutaneous horn, pilar cyst and nevus sebaceus.

Given that the included photographs and figures did not include any identifiable part of patient's face or body, verbal consent for inclusion of these images was obtained from the patient.

\section{References}

[1] Rodgers, R., Jakobiec, F.A. and Hidayat, A.A. (2008) Eyelid Tumors of Apocrine, Eccrine, and Pilar Origins. In: Albert, D.M., Miller, J.W., Azar, D.T., Blodi, B.A., Cohan, J.E. and Perkins, T., Eds., Albert \& Jakobiec’s Principles \& Practice of Ophthalmology, 3rd Edition, Saunders, Philadelphia, 3343-3365. http://dx.doi.org/10.1016/b978-1-4160-0016-7.50256-3

[2] Santa Cruz, D.J. and Walsh, S.N. (2013) Tumors of the Skin. In: Fletcher, C.D.M., Diagnostic Histopathology of Tumors, 4th Edition, Elsevier Inc., Edinburgh, 1680-1795.

[3] Calonje, E., Brenn, T. and Lazar, A. (2012) Tumors of the Surface Epithelium. In: McKee’s Pathology of the Skin, 4th Edition, Elsevier, Edinburgh, 1076-1149. http://dx.doi.org/10.1016/B978-1-4160-5649-2.00024-X

[4] Brownstein, M. (1979) Trichilemmal Horn: Cutaneous Horn Showing Trichilemmal Keratinization. British Journal of Dermatology, 100, 303-309. http://dx.doi.org/10.1111/j.1365-2133.1979.tb06203.x

[5] Wang, Y., Guo, M.F., Liu, B.Y., He, Y.F. and Li, L.F. (2013) A Giant Cutaneous Horn on the Cheek. Journal of Plastic Reconstructive and Aesthetic Surgery, 66, 871-872. http://dx.doi.org/10.1016/j.bjps.2012.11.042

[6] Sathyanarayana, S., Deutsch, G.B., Edelman, M. and Cohen-Kashi, K.J. (2011) Cutaneous Horn: A Malignant Lesion? A Brief Review of the Literature. Dermatologic Surgery, 38, 285-287. http://dx.doi.org/10.1111/j.1524-4725.2011.02225.x 
[7] Al-Zaid, T., Ditelberg, J.S., Prieto, V.G., Lev, D., Luthra, R., Davies, M.A., Diwan, A.H., Wang, W.L. and Lazar, A.J. (2012) Trichilemmomas Show Loss of PTEN in Cowden Syndrome but Only Rarely in Sporadic Tumors. Journal of Cutaneous Pathology, 39, 493-499. http://dx.doi.org/10.1111/j.1600-0560.2012.01888.x

[8] Idriss, M. and Elston, D.M. (2014) Secondary Neoplasms Associated with Nevus Sebaceus of Jadassohn: A Study of 707 Cases. Journal of the American Academy of Dermatology, 70, 332-337. http://dx.doi.org/10.1016/j.jaad.2013.10.004

[9] James, W., Berger, T.G. and Elston, D.M. (2011) Epidermal Nevi, Neoplasms, and Cysts. In: Andrews' Diseases of the Skin Clinical Dermatology, 11th Edition, Elsevier, Philadelphia, 620-674.

[10] Groesser, L., Herschberger, E., Sagrera, A., Shwayder, T., Flux, K., Ehmann, L., Wollenberg, A., Torrelo, A., Bagazgoitia, L., Diaz-Ley, B., Tinschert, S., Oschlies, I., Singer, S., Mickler, M., Toll, A., Landthaler, M., Real, F.X. and Hafner, C. (2013) Phacomatosis Pigmentokeratotica Is Caused by a Postzygotic HRAS Mutation in a Multipotent Progenitor Cell. Journal of Investigative Dermatology, 133, 1998-2003. http://dx.doi.org/10.1038/jid.2013.24

[11] Groesser, L., Herschberger, E., Ruetten, A., Ruivenkamp, C., Lopriore, E., Zutt, M., Langmann, T., Singer, S., Klingseisen, L., Schneider-Brachert, W., Toll, A., Real, F.X., Landthaler, M. and Hafner, C. (2012) Postzygotic HRAS and KRAS Mutations Cause Nevus Sebaceous and Schimmelpenning Syndrome. Nature Genetics, 44, 783-787. http://dx.doi.org/10.1038/ng.2316

[12] Steelman, L.S., Chappell, W.H., Abrams, S.L., Kempf, R.C., Long, J., Laidler, P., Mijatovic, S., Maksimovic-Ivanic, D., Stivala, F., Mazzarino, M.C., Donia, M., Fagone, P., Malaponte, G., Nicoletti, F., Libra, M., Milella, M., Tafuri, A., Bonati, A., Bäsecke, J., Cocco, L., Evangelisti, C., Martelli, A.M., Montalto, G., Cervello, M. and McCubrey, J.A. (2011) Roles of the Raf/MEK/ERK and PI3K/PTEN/Akt/mTOR Pathways in Controlling Growth and Sensitivity to Therapy-Implications for Cancer and Aging. Aging, 3, 192-222.

[13] Mendoza, M., Er, E.E. and Blenis, J. (2011) The Ras-ERK and PI3K-mTOR Pathways: Cross-Talk and Compensation. Trends in Biochemical Sciences, 36, 320-328. http://dx.doi.org/10.1016/j.tibs.2011.03.006

[14] Suster, S., Wong, T.Y. and Mihm, M. (2009) Tumors of the Skin. In: Weidner, N., Cote, R.J., Suster, S. and Weiss, L.M., Eds., Modern Surgical Pathology, 2nd Edition, WB Saunders, Philadelphia, 1890-1945. http://dx.doi.org/10.1016/b978-1-4160-3966-2.00049-7

[15] Reddy, V.B. (2010) Skin and Adnexal Structures. In: Gattuso, P., Reddy, V.B., David, O., Spitz, D.J. and Haber, M.H., Eds., Differential Diagnosis in Surgical Pathology, 2nd Edition, WB Saunders, Philadelphia, 39-210. http://dx.doi.org/10.1016/b978-1-4160-4580-9.00002-2 